\title{
A Review on Assessment of Hybrid Renewable Energy System
}

\author{
Dhanish Madhav \\ M.Tech. Scholar \\ Dept. of Electrical Engineering \\ Jaipur National University
}

\author{
Abhishek Kumar Gupta \\ Assistant Professor \\ Dept. of Electrical Engineering \\ Jaipur National University
}

\author{
Rahul Ranjan \\ Assistant Professor \\ Dept. of Electrical Engineering \\ Jaipur National University
}

\begin{abstract}
For a faster growing economy like India electrical power supply is crucial to overall development where nearly $70 \%$ of population resides in the villages and they are deprived of electrical power supply for more than of 6 to 12 hours a day for their basic household and agricultural needs of power. Deen Dayal Upadhyaya Gram Jyoti Yojana (DDUGJY) is a Government of India (GOI) scheme designed to provide continuous power supply to rural India which is implemented by Rural Electrification Corporation (REC). The grid extension does not permit the energy economic alternative in far off rural areas so Renewable Energy Sources (RES) like solar and wind are adopted, which are never-ending, freely available, environment friendly and widely acceptable as compared to traditional fossil fuels.
\end{abstract}

Renewable Energy (RE) is a pressing need in the 21 st century as non-renewable sources are no longer fit for our energy needs. This is especially important in a country like India, where supply to demand ratio is very low. This review paper represented the assessment of Hybrid Renewable Energy System (HRES).

\section{Keywords}

Government of India (GOI); Deen Dayal Upadhyaya Gram Jyoti Yojana (DDUGJY); Rural Electrification Corporation (REC); Renewable Energy (RE); Renewable Energy System (RES); Hybrid Renewable Energy System (HRES).

\section{INTRODUCTION}

As India is fastest growing economy in the world. For the overall growth of the economy, it is necessary that the agro based economy also contribute to the growth. It is neither doable nor frugal to transmit electricity in the aloof zones where a few families inhabit in the village. That's why our government also initiated decentralized and distributed generation concept under the DDUGJY, previously this scheme was known as Rajiv Gandhi Gramin Vidyutikaran Yojana, which was implemented by Rural Electrification Corporation[13]. Under DDUGJY scheme all villages and households shall be electrified, increase in agriculture yield, business of small and household enterprises shall grow resulting in new avenues for employment, improvement in health, education and banking services, betterment in social security due to availability of electricity, accessibility of electricity to schools, panchayats, hospitals and police stations etc., rural areas shall get increased opportunities for comprehensive development. Or either we can say that Distributed generation and storage enables collection of energy from many sources may lower environmental impacts and improve security of supply. DER systems typically use renewable energy sources, including small hydro, biomass, biogas, solar power, wind power, and geothermal power, and increasingly play an important role for the electric power distribution system. For the better reason of healthy environment this review paper represented the Assessment of Hybrid Renewable Energy System and Paper also tried to focus on the solar-wind hybrid streetlight concept.

\section{LITERATURE REVIEW}

[Md. Monir Hossain, et-al, 2015] have studied a prefeasibility of a hybrid renewable power system at the location of Nijhum Dwip of Bangladesh, which was a detached island from national grid system. The prospect of Solar, Wind and Biomass as renewable components of a hybrid system had explored with the inclusion of a diesel generator to compare the renewable vs. conventional system both economically and environmentally. An emission reduction of almost 3422 ton $\mathrm{CO} 2$ by replacing an equivalent diesel based plant with the optimized system is possible to be accomplished. Almost 11000 people belonging to almost 2000 families live at Nijhum Dwip. In order to calculate residential load we divided the families in Nijhum Dwip based on their income and estimated load for each class. In Nijhum Dwip the average daily radiation is $4.69 \mathrm{kWh} / \mathrm{m} 2 /$ day with an average annual clearness index 0.502 . On the other hand, wind speed in this site is quite below optimum level $(4 \mathrm{~m} / \mathrm{s})$. From the cost analysis it is clearly seen that, this optimized system is the most cost effective system having per unit cost of energy about BDT 19.926. As the hybrid system was $100 \%$ renewable, there is very low emission of greenhouse gases e.g. $\mathrm{CO} 2, \mathrm{SO} 2, \mathrm{NOX}$ and other pollutants.

[Shekhar K. Pawar, et-al, 2014] have presented a technoeconomic optimization of a PV/Wind grid connected system for supplying electricity to a residential house in the city of Baramati, Maharashtra. The considered house had a maximum load demand of $3 \mathrm{kWh} /$ day and a peak of 0.225 KWh. Baramati has a semi-arid climate, summer is moderately hot and dry and winter was chilly and wetter, 
average temperature range of $40^{\circ} \mathrm{C}$ in summer and $20^{\circ} \mathrm{C}$ during winter. Wind speed varies between $3 \mathrm{~m} / \mathrm{s}$ and $5 \mathrm{~m} / \mathrm{s}$. The $\mathrm{PV} /$ wind/grid connected design contains one $1 \mathrm{~kW} \mathrm{PV}$ array, one $1 \mathrm{KW}$ wind turbine and a $3 \mathrm{~kW}$ power converter, with a total NPC of Rs.2,73,790 and a COE of Rs.4.95/kWh. The electricity delivered by the PV-wind-grid combination was Rs.4.95/kWh. The cost-effective scenario integrating renewable energy suggests that $49 \%$ of the yearly house load could be supplied by solar energy and $34 \%$ by wind turbine. In this case the electricity contribution by grid was $18 \%$ which is minimum as compare to other output results.

[Rimantas Pranas Deksnys, et-al, 2014] paper shown the inter correlation between power generations in solar photovoltaic and wind farms, and that between power generation and the load had determined. Solar energy was not a considerable source of renewable energy, as Lithuania receives $1,000 \mathrm{kWh}$ per square meter per year with about 80 percent of it is received during the April - September period. The maximum correlation coefficient of variation in power generation of 0.46 , and standard deviation of $4.32 \mathrm{MW}$ obtained between the solar power plants shows that development of solar power plants must be well balanced to the local demand for load. The correlation of variation in power generation between the solar power plants and load was found to be positive, their joint standard deviations were found not to increase, consequently penetration of solar power plants into the electrical power systems is not expected to require for significant operating power reserves.

[Muhammad Khalid, et-al, 2014] This paper represented a method to combine wind and solar photovoltaic (PV) powers in an optimal ratio to match the power demand at a particular site. The idea of advantageously combining the complementary power production characteristics of both renewable energy (RE) resources has clear benefits for renewable power plants. The proposed strategy aims to match the required power demand with an added advantage of smoothing out those variations in the individual renewable powers without using the energy storage. The effectiveness of the proposed approach is depicted from the simulation results validated with real-world wind farm and solar PV data. The proposed strategy has been tested by simulations using real solar PV and wind power data of 5-min resolution. The wind farm observation data used consists of output power of the Roaring 40sWoolnorth wind farm in Tasmania, Australia. The two-fold benefits of the proposed hybrid power system lie in suppression of the variations in the output power as compared with individual wind and solar power outputs without using any storage technology, and primarily demands matching based on the complementary characteristics of both renewable energy resources.

[Sonam Mishra, et-al, 2014] demonstrate the architecture of a hybrid system is proposed which is based on solar photovoltaic and wind energy systems. The proposed architecture consists of solar PV and wind energy system. In solar PV system MPPT technique is applied to maximize power output, a boost converter is employed to raise DC voltage and its output is fed to a three phase PWM inverter for converting
$\mathrm{DC}$ voltage to $\mathrm{AC}$ at $50 \mathrm{~Hz}$ frequency. In wind energy conversion system PMSG is driven by two masse drive train based wind turbine with zero pitch angles. In India sector wise consumption of Electrical Energy (utilities) during 2011-2012 in percentage was 22 in Domestic, 17 in Agriculture , 45 in Industry, 9 in Commercial, 2 in Traction and railways, 5 in others. By 2013 total installed capacity of electrical power in India is $2,25,793.10 \mathrm{MW}$, in which state sector is contributing 89,092.12 MW, central sector 65,612.94 MW and private sector 71,088.04 MW. Fuel wise power generation capacity varies as Total Thermal power is $153,847.99 \mathrm{MW}$ in which Coal is $132,288,39 \mathrm{MW}$, Gas is $20,359.85 \mathrm{MW}$ and Oil is $1,199.75 \mathrm{MW}$, Hydro (Renewable) is $39,623.40 \mathrm{MW}$, Nuclear is $4,780.00 \mathrm{MW}$ and renewable energy sources is 27,541.7IMW. In Hybrid system number of electrical power generators and electrical power storage components are combined together to meet the electrical power demand of remote as well as rural area or even a whole community. $\mathrm{Tt}$ is also used as a standalone power system, is an autonomous system that supplies electricity to the user load without being connected to the electrical power grid. The results of simulation showed that the system, performance is excellent and that the mathematical models and control techniques developed in this paper can also be used to design and control the other different topologies of Solar PV and Wind hybrid energy system. In this proposed system both sources are supplying $1 \mathrm{KW}$ load which is used independently and combination. In future this hybrid system can be made fully automatic and more efficient with application of artificial intelligence system. This system is very useful as standalone power supply setup for mobile communication tower, rural areas etc.

[Dev Gaurav, et-al, 2014] have intended to identify the geographical areas for solar and wind energy generations at low cost. It has been achieved by monitoring atmospheric weather conditions, such as temperature, humidity, wind speed and light intensity. Design was based on remotely operated system with sensors, which gathers weather information and transmits measured values to the ground. They have considered a number of options to device atmospheric weather monitoring system at low cost, long lasting and durable for extreme weather conditions. The cost of the system was estimated to be nearly thirty dollars. It was highly reliable and deployable, and very useful utility in a country like India. The system could be easily deployed at areas to keep track of continuous climatic changes. The system was operated by battery, and was expected to run with a long life span, because of the system optimizations done for maximum power savings. Our system weighs only less than $150 \mathrm{gm}$, and was easily floatable and recoverable with the help of a simple Hydrogen balloon. The main characteristic of this report was regular sampling of data at every 30 seconds from the deployed device, and communicates to the ground station via GSM cellular networks. Power generation feasibility is mapped frequently and optimal generation is checked for different values of temperature, humidity and wind speed. 
[Dan Shen, et-al, 2014] have proposed a standalone distributed hybrid power system which consists of solar power, wind power, battery storage and the load. A control strategy was introduced to maximize the simultaneous energy harvesting from both renewable sources. There were two main branches in the system, thus two new energy sources could compensate each other to some extent under different climates. The first stage converters are controlled by MPPT controller and capture the maximum power from wind and solar respectively. The second stage converters are controlled by local controller as a constant voltage sources (CV). The control action as voltage source is determined by the supervisory controller. Both energy sources are connected in parallel to a common dc bus through their individual dc-dc converters. The load and battery are directly connected to dc bus. CV controller creates a controlled voltage source to inject current to the system and maintain the voltage. Models of a horizontal axis wind turbine and a PV array and their MPPT power tracking controllers and adaptive voltage controllers and supervisory controller were built in MATLAB/Simulink. A supervisory control strategy was proposed to generate the maximum power from these renewable energy sources and battery while connected to a common coupling point. A robust and smooth switching from MPPT to power tracking mode was obtained in both power sources. Simulation results demonstrated an accurate operation and applicability of the proposed method.

[Vivek Raman, et-al, 2007] have represented the study carried out to evaluate an annual thermal and energy efficiency of a hybrid photovoltaic thermal (HPVT) air collector for different Indian climate conditions, of Srinagar, Mumbai, Jodhpur, New Delhi and Bangalore. The study has been based on electrical, thermal and energy output of the HPVT air collector. Further, the life cycle analysis in terms of cost $/ \mathrm{kWh}$ has been carried out. The HPVT system can be used as air collector/water collector. A HPVT air collector consists of a PV module with an air duct mounted below the PV module. The air is passed through the duct by using a fan. The air gets heated by using the thermal energy available at the bottom of the PV module. In case of HPVT water collector, water is used in place of air. The no. of years required to recover energy invested, i.e. in manufacturing, transportation, installation, operation and maintenance of the system while in use is called EPBT(Energy Payback Time). It was evident that the electrical, thermal and energy outputs for the climatic conditions of Jodhpur are the best when compared with other climatic conditions covered in the study due to higher insolation and sunshine hours. The variation in solar radiation in the range $1025-1175 \mathrm{~W} / \mathrm{m} 2$, the thermal and energy efficiency drop by about $10 \%$ and $5 \%$, respectively. It is also observed that the energy efficiency is $40-45 \%$ lower than the thermal efficiency in the range of solar radiation mentioned above. Amongst the climatic conditions covered under the study, Jodhpur is the best for use of hybrid photovoltaic thermal (HPVT) air collector. The energy payback time (EPBT) of the HPVT air collector without balance of system (BOS) is about 2 years, which can further be reduced for higher solar radiation, longer sunshine hours and number of clear days in a year. There is marginal effect of the life of the HPVT air collector on life cycle conversion efficiency (LCCE) after 50 years. Thus, minimum period of 50 years of the present system is economical.

[Shiv kumar, et-al, 2009] have presented the life cycle cost analysis of the single slope passive and hybrid photovoltaic (PV/T) active solar stills, based on the annual performance at $0.05 \mathrm{~m}$ water depth. Photovoltaic-thermal (PV/T) technology refers to the integration of a PV module and conventional solar thermal collector in a single piece of equipment. The rationale behind the hybrid concept is that a solar cell converts solar radiation to electrical energy with peak efficiency in the range of $9-12 \%$, depending on specific solarcell type and thermal energy dissipated for water heating. More than $80 \%$ of the solar radiation falling on photovoltaic (PV) cells is not converted to electricity, but either reflected or converted to thermal energy. The economics of any energy system is essential to understand the cost of production and economic payback period on the investment to reduce the risk of project failure. The life cycle cost analysis of solar still depends on several key variables such as initial investment, rate of interest, annual distillate yield, maintenance cost, life time of solar still, production cost of distilled water, selling price of distilled water, salvage value of the system, etc. The utilization of the hybrid (PV/T) active solar stills as a source of distilled water for commercial purposes should be determined by its economics. The better economic return on the investment depends on the production cost of the distilled water and its applicability. The annual costs of the passive and hybrid active solar distillation systems have been calculated using annualized (UA) life cycle costing . The life cycle cost analysis for both the solar stills has been carried out by considering the expected useful life of 15 years and 30 years for FPC and PV module, respectively. The experiments were carried out in the solar energy park of Indian Institute of Technology, New Delhi (India) on the passive and hybrid $(\mathrm{PV} / \mathrm{T})$ active solar stills under tropical climatic condition for the period, April-March, 2006-2007. During the course of experimentation, underground water has been used to distillate for commercial purposes such as in battery, hospital, dispensary etc. Experimentation for the three different water depths $(0.05,0.10$ and $0.15 \mathrm{~m})$ has been carried out on different typical days for $24 \mathrm{~h}$. The annual yield (for 260 clear days) obtained from hybrid active solar still $(1203.46 \mathrm{~kg})$ is around 3.5 times higher than the passive solar still (343.36 $\mathrm{kg}$ ). The net power saved is around $83.2 \mathrm{~kW} \mathrm{~h}$, which can be utilized for other applications when such systems are connected in array. The Payback periods of the passive and hybrid (PV/T) active solar stills are obtained in the range of 1.1-6.2 years and 3.3-23.9 years, respectively, for the selling price of distilled water in the range of Rs. 10 to Rs. $2 / \mathrm{kg}$. Therefore, passive solar stills are acceptable for potable use.

[P.V. Suresh, et-al, 2013] have evaluated the life cycle cost of a hybrid renewable systems combining solar, wind, biomass energy sources to meet the demand of energy center. The main objective of this study was to compare the life cycle cost of different combination of hybrid systems and individual 
standalone systems. The most economical hybrid system with lowest life cycle cost had determined. From the analysis it was found that life cycle cost of standalone solar energy system is highest.

[Ilze Priedite, 2014] has illustrates economical grid-connected onshore micro wind turbines. Carbon dioxide emissions in Latvia currently reaching 4.1 tons of $\mathrm{CO} 2$ per capita per year. Total wind energy potential in Latvia is estimated up to 1.5TWh. Approximately $66 \%$ of the annual electricity generated with solar cells is produced between April to August, i.e., there are five months with high productivity and seven months with low productivity in Latvia. A case study was carried for 3 solar cells with rated power $1 \mathrm{~kW}, 3 \mathrm{~kW}$ and $5 \mathrm{~kW}$. The solar-cell system consists of CNPV 205W mono crystalline panels, SMA inverter network Sunnyboys1200 and monitoring system (SMA Web box and SMA Sensor box) connected to the internet. Panels have south-facing orientation on a slanted roof (150 roof angle). The system is connected to the power grid. When solar energy is insufficient, additional energy was purchased from power grid. The prime cost of electricity was calculated for two cases solar cell is used 10 years (workmanship warranty period) and solar cell is used 25 years $(80 \%$ output warranty period). Breakdown of households by annual average consumption of electricity in Latvia shows increase energy consumption from year 1996 to year 2010. Increase in annual expenditure on electricity produced by onshore micro wind turbine is more than $26.4 \%$.

[K. Nagasujatha, et-al, 2015] have designed a hybrid renewable energy system with battery backup. The meteorological data of Solar Radiation, hourly wind speed for the Department of Electrical and Electronics Engineering, Jawaharlal Nehru Technological University Hyderabad (Latitude18026' N, longitude is $7907 ' \mathrm{E}$ ) were taken to meet the primary load of $100 \mathrm{Kwh} / \mathrm{day}, 28 \mathrm{Kw}$ peak load. The evaluation of the correct type of RES is needed to optimize the system. Usually through designed software packages like HOMER, RETSCREEN, etc. can be used for modeling, analysis and optimization of RES. HOMER software package can be used for design, model and analysis to determine the optimal architecture, structure, size and control strategy of the HPS. It can perform comparative economic and modeling analysis on a distributed generation power system in order to get the best solution in terms of cost, performances, size and structure. The combination of a diesel generator $(15 \mathrm{KW})$ and a minimum of 60 batteries is economically most feasible with COE $0.658 \$ / \mathrm{KWh}$ and a minimum NPC of $\$ 306,891$ without any annual energy shortage. In this condition, the total NPC grows significantly and the contribution towards the Monthly Average Electric Production of the Proposed System by Diesel Generator was $55 \%$, and Wind Turbine is $45 \%$. When the peak demand was low, the available energy from each renewable source will be stored in batteries.

[Dattatraya. N. Gaonkar, et-al, 20114] have been presented roof top wind solar micro-grid system. The developed micro grid system consists of wind and solar based distributed generation systems along with necessary battery energy storage and power electronic converter interface. The performance of the developed model has been studied and results are reported in this work. The result shows that the drastic variation in wind power output in the selected location. The performance results also shows that the variation in wind can be effectively taken care by combined operation with PV system along with battery storage. The study indicates that the micro grid concepts can take care effectively the variable nature of wind and PV source to supply the demand and improve the overall reliability of the system.

[AN Ce-ce, et-al, 2015] In this paper the hardware system of the wireless monitoring system was produced, here ZigBee technology was used to realize the communication between the street lamps, at the same time to implement the real-time monitoring of the wind and solar hybrid street lamps. ZigBee was a new developed technology based on the IEEE 802.15.4 wireless standards about the networking, security, and application software of wireless communication technology its typical characteristic was close, low power consumption and low rate, low cost, etc. In this wind and solar hybrid street lamps monitoring system, every street lamp includes a wireless sensor module CC2530, each ZigBee network area has a concentrated control microprocessor MPS430.Through the form of ZigBee wireless network, the data between street lamps can be collected for communication and control. The data was dealt with the processor to the monitoring center to complete the transfer through GPRS module GTM900C, the monitoring center to control the reaction.

[Vinesh Thiruchelvam, et-al, 2015] The project was developed as a hybrid solution to capture the combined high levels of solar radiation and monthly average wind speed in Malaysia for which location of KotaKinabalu was selected. The Hybrid Solar Wind Energy Tower (HSWET) combines the functions of wind turbines in parallel with solar panel hence having a higher total of renewable energy values. In order to determine the efficiency of the HSWET, the output power is measured and monitored. Furthermore, the efficiency of HSWET design was compared with an existing solar hybrid system already in the market and the results of the proposed HSWET system showed a higher efficiency. Experimental results have proven that not only was the HSWET cheaper in assembly cost but it also has a more constant output. The simulated yearly energy production was $34.89 \mathrm{MWh}$ and the actual annual energy production was $22.45 \mathrm{MWh}$. In addition, the system required diesel costing Euro $\$ 1167.00$ per year. The efficiency at $64.35 \%$ is lower than a potentially scaled up HSWET.

\section{SOFTWARE DESCRIPTION}

The HOMER is micro power optimization software developed by Mistaya Engineering, Canada for the National Renewable Energy Laboratory (NREL) USA, which can be used for design, model and analysis to determine the optimal architecture, structure, size and control strategy of the HPS. It can perform comparative economic and modeling analysis on a distributed generation power system in order to get the best solution in terms of cost, performances, size and structure. For systems that include batteries or fuel-powered generators, 
HOMER also decides for each hour how to operate the generators and whether to charge or discharge the batteries.

\section{CONCLUSION}

The price of fossil fuel increases with the distance of the location, hybrid energy systems could be an appropriate technology to reduce fuel consumption and environmental hazards. The paper studied local weather data for specific location, methodology is developed for calculate output of component in renewable hybrid system, economic feasibility of renewable energy in supplying electricity to a household. Hybrid systems are one of the most promising applications of renewable energy technology in remote areas, where the cost of grid extension is high.

\section{ACKNOWLEDGMENTS}

The authors acknowledge the support and encouragement of faculty members of electrical engineering department, Jaipur National University, Rajasthan, India.

\section{REFERENCES}

[1] S. Kumar and G. N. Tiwari, "Life cycle cost analysis of single slope hybrid (PV/T) active solar still," Appl. Energy, vol. 86, no. 10, pp. 1995-2004, 2009.

[2] V. Raman and G. N. Tiwari, "Life cycle cost analysis of HPVT air collector under different Indian climatic conditions," Energy Policy, vol. 36, no. 2, pp. 603-611, 2008.

[3] V. Thiruchelvam, G. Tan, and J. Ao, "Design and Implementation of A Hybrid Solar Wind Energy Tower," pp. 371-375, 2015.

[4] ctrification," 2014 Int. Conf. Adv. Eng. Technol. ICAET 2014, no. Icaet, pp. 2-7, 2015.

[5] K. S. P.V. Suresh, "Life cycle cost assessment of sola wind biomass hybrid energy system for energy centre MANIT Bhopal," pp. 635-639, 2013.
[6] I. Priedite, "Economic Asse essment of Onshore Mi icro Wind Turbines and So olar Cells for Power Ge eneration in," pp. 400-405, 2014.

[7] D. Gaurav, D. Mittal, B. Vaidya, and J. Mathew, “A GSM based low cost weather monitoring system for solar and wind energy generation," Fifth Int. Conf. Appl. Digit. Inf. Web Technol. (ICADIWT 2014), pp. 1-7, 2014.

[8] C. Science, E. Engineering, and M. Pradesh, "Modeling and Simulation of Solar Photo-Voltaic and PMSG Based Wind Hybrid System," 2014.

[9] H. Patsamatla, V. Karthikeyan, and R. Gupta, "Universal maximum power point tracking in wind-solar hybrid system for battery storage application," 2014 Int. Conf. Embed. Syst., no. Ices, pp. 194-199, 2014.

[10] M. Khalid, A. V. Savkin, and V. G. Agelidis, "Optimal hybrid wind-solar system for matching renewable power generation with demand," IEEE Int. Conf. Control Autom. ICCA, pp. 1322-1326, 2014.

[11] D. N. Gaonkar, N. S. Jayalakshmi, and P. Raghvendra, "Performance study of roof top wind solar microgrid system in isolated mode of operation," 2014 IEEE Int. Conf. Power Electron. Drives Energy Syst. PEDES 2014, no. 3, pp. 1-6, 2014.

[12] D. Rimantas Pranas and S. Aldas, "Modelling and Analysis of Wind and Solar Generation," pp. 139-142, 2014.

[13] O. P. Kothari and V. S. Chandrakar, "Optimization ofRenewable Energy Sources for Hybrid Power Generation," 2016.

[14] S. Barua and M. A. Matin, "Dwip using hybrid renewable technology," no. November, pp. 4-6, 2015.

[15] R. R. Kumar, "Off-Grid and On-Grid Connected Power Generation: A Review," vol. 164, no. 9, pp. 12-16, 2017. 